\title{
Methods to Test the Compressive Strength of Earth Blocks
}

\author{
Guanqi Lan $\mathbb{D}^{1},{ }^{1}$ Sisi Chao, ${ }^{2}$ Yihong Wang, ${ }^{3}$ and Ying Cui ${ }^{1}$ \\ ${ }^{1}$ School of Mechanical Engineering, Xi'an Shiyou University, Xi'an, Shaanxi Province 710065, China \\ ${ }^{2} X i$ 'an Technological University, Xi'an, Shaanxi Province 710021, China \\ ${ }^{3}$ School of Civil Engineering, Chang'an University, Xi'an, Shaanxi Province 710064, China \\ Correspondence should be addressed to Guanqi Lan; 201202@xsyu.edu.cn
}

Received 25 May 2021; Revised 17 July 2021; Accepted 20 July 2021; Published 27 August 2021

Academic Editor: Luís Evangelista

Copyright (c) 2021 Guanqi Lan et al. This is an open access article distributed under the Creative Commons Attribution License, which permits unrestricted use, distribution, and reproduction in any medium, provided the original work is properly cited.

\begin{abstract}
The efficient design of new earth structures and the restoration of old structures both require a reliable assessment of the compressive strength of earth materials. However, there is still much debate on the best method to accurately measure the compressive strength of earth blocks. To solve the problem of measuring the compressive strength of the earth block, the cube specimen, the half-block stacked specimen, and the full-size block specimen are used to measure the compressive strength of the molded adobe and rammed adobe, respectively, considering the influence of the specimen preparation process, loading direction, capping, and other factors. By comparing and analyzing the stress state, failure mode, and compressive strength of the specimen under various test methods, a compressive strength test method of earth blocks is determined, which is simple to operate, easy to standardize, and as close as possible to the actual strength of the blocks. The results show that the full-size block compression test method along the block thickness direction should be preferred to test the compressive strength of the earth block. The standard specimen obtained by cutting the full-size block is not suitable for the test of the compressive strength of the earth block; it can effectively solve the problem that the compressive strength of the small-thickness earth block cannot be directly measured by cutting the full-size block in half and stacking it, but it is not recommended to use the binder to bond the two half-blocks. When comparing the compressive strength of the earth blocks, the conversion coefficient related to the height-to-thickness ratio of the specimen cannot be used to convert the compressive strength. Still, the anisotropy of the material strength should be considered.
\end{abstract}

\section{Introduction}

Since the start of industrial civilization, the construction industry has caused a high level of pollution due to the exploitation, processing, and transportation of building materials [1]. Particularly in developing countries, the continued rapid population growth necessitates more construction and the use of industrial building materials [2]. The use of local materials to build housing is an important strategy to counter our worsening global environmental problems [3]. Earth materials are some of the oldest local materials and are widely used in dwelling construction all over the world. In fact, one-third of the world's population still lives in earthen dwellings $[4,5]$. In the last twenty years, this original material has found new attention from the construction industry because of its low energy consumption and excellent ability to regulate indoor temperature and humidity [6].
The efficient design of new earth structures and the restoration of older construction require the reliable assessment of the mechanical properties of earth materials. Compressive strength is considered an essential mechanical parameter of materials $[7,8]$. However, there is no universally accepted testing method to measure the compressive strength of earth blocks. Due to the confinement produced by friction between the loading plate and the compression surface of the sample during testing, the aspect ratio, compression area, and the method used for the treatment of the compression surface all can significantly affect the measurement of compressive strength $[9,10]$. Samples with a small aspect ratio and large compression area are more vulnerable to the strong confinement imposed by the loading plate. This confinement restricts the lateral strain of the samples and thus artificially enhances the compressive strength. 
Like cement, concrete, and other conventional building materials, the loading steel plate also constrains the earth block in the compression test process. However, due to the plastic properties of earth materials (which cannot be regarded as brittle materials), the constraint effect on earth materials is more significant, especially for that traditional adobe with small thickness. Therefore, the test method significantly influences the measurement of the compressive strength for the earth block. The ultrahigh compressive strength value may be measured in some cases (the earth block with a small height-to-thickness ratio). To solve the problem of measuring the compressive strength of the earth block, the cube specimen, the half-block stacked specimen, and the full-size block specimen are used to measure the compressive strength of the molded adobe and rammed adobe, respectively, considering the influence of the specimen preparation process, loading direction, capping, and other factors. By comparing and analyzing the stress state, failure mode, and compressive strength of the specimen under various test methods, a compressive strength test method of earth blocks is determined, which is simple to operate, easy to standardize, and as close as possible to the actual strength of the blocks.

\section{Normative Review of Strength Test Methods for Earth Block}

Numerous studies address compressive strength test problem for earth block by reducing the friction on the compression surface and increasing the aspect ratio of the sample. In one strategy, an even interlayer is inserted between the surface of the sample and the plate of the testing machine to reduce the friction. Ciancio and Gibbings [11] investigated the effect of different interlayers on the compressive strength of molded earth blocks. Cylindrical samples with an aspect ratio of 2 and made of stabilized earth materials (limestone soil and $10 \%$ cement) were subjected to simple compression tests. Two interlayers of $10 \mathrm{~mm}$ thick soft plywood blocks and $5 \mathrm{~mm}$ thick layers of dental plaster were tested for their ability to reduce the friction on the compression surface. They found that the two interlayers used in the study did reduce friction, but had no significant effect on the compressive strength of the samples. They also tested the compressive strength of cylinders of different aspect ratio with Teflon sheet at the sample ends and found that the presence of the Teflon sheet reduced the influence of aspect ratio on compressive strength. Silveira et al. [12] used a capping mortar to treat the compressive surface of different-shaped samples that were drilled from earth blocks. They found that this process reduced the influence of sample shape on compressive strength that was minimized by treatment. However, Aubert et al. [13] conducted a simple compressive test on $5 \times 5 \times 5 \mathrm{~cm}^{3}$ cubes with or without Teflon capping and concluded that Teflon capping at the sample ends has no significant effect on compressive strength and its variability.

In another approach, the effects of confinement were addressed by standardization of the sample size. Manufacturing methods of standard size samples generally fall into two categories: samples sawn from earth blocks and samples made to conform to the same composition as earth blocks. For samples sawn from earth blocks, the sawing process may cause damage to the sample that can increase variability. For example, Illampas et al. [14] manufactured standard cylinder, cube, and prism samples that were cut and cored from sample earth blocks. The compressive strengths of these samples without any capping were measured by simple compression test. The results show significant variability, and in the worst case (cube), the coefficient of variation (CV) of the compressive strength for the four samples was 76.8\%. Similarly, Aubert et al. [13] used a simple compression test to measure the compressive strength of cube and prism samples of block and found a maximum $\mathrm{CV}$ of $27 \%$. It is difficult to obtain standard samples from blocks by cutting, coring, or sawing, and these methods can result in considerable variation in the size of the standard sample. Standard samples that are prepared separately rather than cut from blocks can effectively reduce the damage caused by cutting or sawing. However, the results of comparative compressive strength testing of standard samples and blocks of the same material often show no significant correlation [15].

Several studies report increased aspect ratio of samples by cutting the blocks in half and stacking or bonding them together [16-18]. In 1994, the CEB RILEM Technical Committee 164 [19] proposed a test method (RILEM procedure) to measure the compressive strength of compressed earth block (CEB) samples. In this method, the CEBs were halved, stacked, and bonded using a mortar bed joint. The real stress state of CEB in masonry can be simulated in this way, and the earth mortar contributes to uniform stress transfer between stacked blocks. In some tests [19], the compressive strengths of CEBs were measured by the RILEM procedure and compared with the strengths obtained from simple compressive tests on cylindrical samples with an aspect ratio of 1.5 . The results showed that the compressive strength measured by the RILEM procedure was lower than that of the cylindrical samples (by approximately 15\%). Because the strength and stiffness of the mortar are lower than that of the CEB, the joint weakened the integrity of the samples. Based on the RILEM procedure, the France Standard XP P13-901 [20] used a traditional cement mortar (sand and cement) as the bonding material instead of earth mortar. The RILEM procedure addresses the earlier problems and allows the accurate measure of the compressive strength of earth blocks, especially those with sizeable compressed area and small aspect ratio. However, the type of mortar joint has a significant influence on the compressive strength and the quality of the mortar joint may vary between experiments, which will add to the variability of the results.

The three-point bending test was developed to enable on-site quality control testing of materials without laboratory testing equipment [21]. This method can be performed without sophisticated devices, since the load required to induce sample failure is much less than that required for the simple compression test. However, the influence of shear, size effect, and arch effect are neglected in this strategy, 
which can lead to significant variability of the results [22]. Although some studies [23, 24] established the relationship between compressive strength and flexural strength of earth block, significant errors remain in this calculation.

The existing research mainly explored the suitable test methods for the compressive strength of the earth block from the following four directions:

(1) Standard specimen: the block is cut into standard shape and size samples, or samples with standard shape and size are made with the same manufacturing process and raw materials as the block. This method is similar to the compressive strength test of cement materials.

(2) Full-sized block: the compressive strength of the fullsized block is tested directly.

(3) Half-block stacked specimen: the block is cut into two half-blocks of equal size, and the two half-blocks are stacked to increase the height-to-thickness ratio.

(4) Indirect test: 3-point bending test was carried out on the full-size block, or splitting test was carried out on the standard cylinder sample.

At present, most of the test methods used to test the compressive strength of earth blocks refer to the strength test methods of existing cement-based blocks and fired blocks or the improved test methods based on them [25-27]. However, the applicability of these test methods for earth materials has not been systematically demonstrated. At the same time, compared with fired block or concrete block, the nonbrittle properties of earth block lead to the more significant influence of hoop effect in the compression test. When the height-to-thickness ratio of the block is too small, the compressive strength of the earth block may not be measured. Although the existing research has put forward many ideas to solve this problem, there are still various defects in various test methods [13], and so far, there is no standard test method to guide the compressive strength test of earth blocks. Therefore, it is of great significance to determine the applicability and characteristics of the existing test methods and then put forward the optimum test method of compressive strength for earth block.

\section{Materials and Methods}

3.1. Materials. Earth materials from the southern and central parts of Shaanxi, China, were used as the raw material for block making. The composition, Atterberg limits, optimum moisture content, and maximum dry density of the soil in two regions were measured according to Chinese standard SL237-1999 [28], as shown in Table 1.

3.2. Sample Preparation. A representative molded earth block and compacted earth block were used in this experiment. These blocks were manufactured by skilled workers. The molded adobe (Figure 1(a)) was manufactured from soil (EM-1) with a moisture content of $24 \pm 2 \%$ and formed in a mold, as shown in Figure 2(a). The compacted block (Figure 1(b)) was made by using soil (EM-2) with a moisture content close to the optimal moisture content (19.5\%) into the mold and then ramming it without stratification, as shown in Figure 2(b). The compacted block was composed of natural soil without any admixture. The molded adobe was mixed with straw at a mass ratio of about $1 \%$, and the straw length was $7-10 \mathrm{~cm}$. The compaction direction for the rammed adobe was as shown in Figure 1(b). Cube samples (molded and compressed) with a length of $100 \mathrm{~mm}$ were prepared independently without cutting from full-size blocks (Figure 1). The full-size blocks and cube samples were cured in a laboratory until the mass of the blocks was constant. The densities of the two blocks were measured according to China standard GBT 2542-2012 [29] and are presented in Table 2.

The stacked half-blocks were obtained after saw-cutting full-size blocks according to China standard GBT 2542-2012 [29]. In this study, the influence of binder on the compressive strength of stacked half-blocks was not considered, and half-blocks were simply stacked without any binder (Figure 1).

3.3. Testing Procedure. The geometric dimension of samples and the loading direction for each test are listed in Table 3. Because of the change in aspect ratio and the difference in the manufacturing technique (and the direction of compression), the compressive strength of the earth block depends strongly on the loading direction [13]. Thus, it is essential to consider the loading direction of the full-size blocks and cube samples and to consider the $x$-, $y$-, and $z$ directions (Figure 1).

For the stacked half-blocks, the loading direction was parallel to the $z$-direction. 10 samples were prepared for each group. Uniaxial compression tests were carried out using a hydraulic press with a capacity of $300 \mathrm{kN}$. In all cases, the tests were run at a constant rate of $0.2 \mathrm{kN} / \mathrm{min}$. The treatment of the contact surface between the block and the loading plate can have a strong effect on compressive strength. Thus, in order to ensure the comparability of the test results, no specific capping was used for blocks and samples.

\section{Results}

4.1. Direct Compression Tests on Full-Size Blocks. Table 4 shows the compressive strength of molded and rammed adobes measured directly on full-size blocks in three orientations: $x, y$, and $z$. For each series of results, the maximum, minimum, and mean values are presented. The variability of the results is reflected by the coefficient of variation expressed in \%. The results obtained on the two types of blocks show that the loading direction had a significant influence on sample compressive strength. This influence may be directly related to the aspect ratio of sample changes with loading direction. As expected, an increase in the aspect ratio led to a decrease in the compressive strength due to the constraint effect. The data presented in Table 4 shows that the mean compressive strength of the molded adobes ranged from $0.51 \mathrm{MPa}$ 
TABLe 1: Physical parameters of soil.

\begin{tabular}{lcccccccc}
\hline \multirow{2}{*}{ Label } & \multicolumn{3}{c}{ The composition of the soil (\%) } & LL $(\%)$ & PL $(\%)$ & OMC $(\%)$ & $\rho_{d \text {-max }}\left(\mathrm{g} / \mathrm{cm}^{3}\right)$ \\
& Clay & Silt & Sand & Gravel & & 18.2 & 1.93 \\
EM-1 & 17.6 & 38.5 & 36.1 & 7.8 & 33.6 & 17.2 & 1.7 \\
EM-2 & 25.2 & 30.7 & 41.2 & 2.9 & 38.9 & 21.7 & 19.5 \\
\hline
\end{tabular}

EM-1: earth materials from the southern part of Shaanxi; EM-2: earth materials from the central part of Shaanxi; LL: liquid limit; PL: plastic limit; OMC: optimum moisture content; $\rho_{d \text {-max }}$ : maximum dry density.

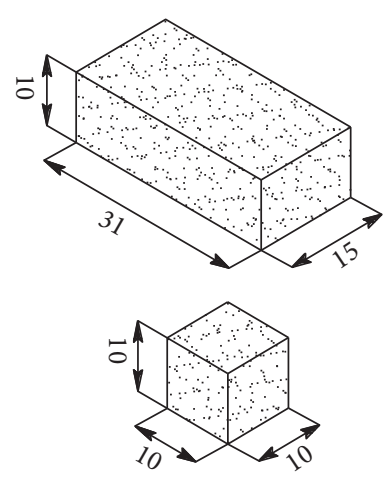

(a)

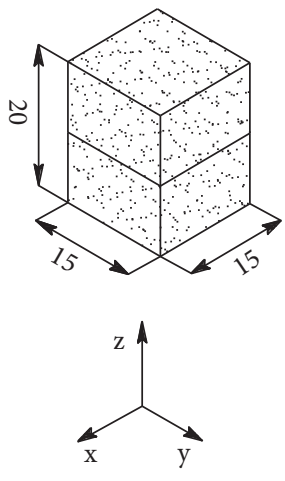

)

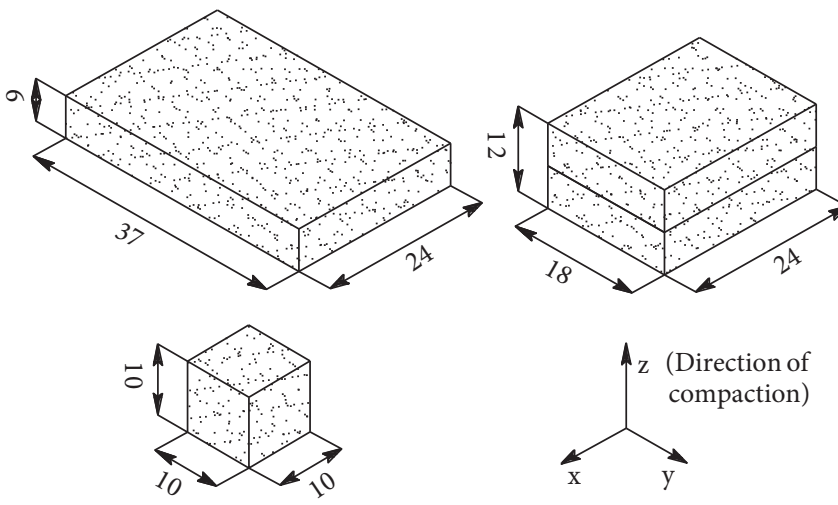

(b)

Figure 1: Preparation of samples. (a) Molded adobe. (b) Rammed adobe (mm).

( $y$-direction) to $1.28 \mathrm{MPa}(z$-direction), and that of the rammed adobes ranged from $1.41 \mathrm{MPa}$ ( $x$-direction) to 1.62 $\mathrm{MPa}$ ( $y$-direction). The compressive strength of rammed adobes cannot be measured when the loading direction in the $z$-direction, as previously reported by Aubert et al. [13], who proposed that samples with small height and large section area showed an enhanced confinement effect. The sample can be gradually compacted under vertical load and horizontal restraint, but it is impossible to reach the breakdown point of the sample.

The data presented in Table 4 show the high variability of compressive strength. For the two types of blocks, the variability of compressive strength increased with the aspect ratio. With loading in the $y$-direction, the compressive strength measurements for the ten molded adobes ranged from 0.37 to $0.67 \mathrm{MPa}$, and those of the ten rammed adobes ranged from 0.82 to $2.01 \mathrm{MPa}$. This considerable variability in the compressive strength of earth blocks is due to the fact that the increase of aspect ratio led to the unstable failure of some samples (Figures 3(b) and 3(c)). Overall, the variability in the compressive strength of rammed adobes was higher than that for the molded adobes. This can be explained by artificial compaction causing a significant difference in the density of each block. The coefficient of variation of density for the rammed adobes was $5.3 \%$, higher than that of the molded adobes (3.7\%).

The block compression test can result in one of three failure modes: axial compression failure, shear failure, and local failure, as shown in Figure 3. Shear failure and local failure occur only in the $x$ - and $y$-directions loading. For $z$ direction loading, all samples showed all axial compression failure.
In axial compression failure mode, slight vertical cracks appeared in the weak part of the samples, and then the cracks expanded. The compressive region is separated into two or more independent pressure-bearing surfaces by cracks. Due to the inhomogeneity of earth materials, the strength of each pressure-bearing surface was different. A huge crack formed along the failure surface after the destruction of some vulnerable pressure-bearing surfaces, and the sample was then crushed or partially destabilized.

In the samples with shear failure, inclined cracks appeared, or a vertical crack became gradually tilted during the expansion process. The shear stress produced by the cracking surface promoted the further expansion of cracks. Finally, fracture penetration led to the shear failure of the sample. The number of cracks in samples with shear failure was less than that in axial compression samples, and generally, there was apparent shear fracture.

For local failure mode, the local crushing failure occurred on the pressure-bearing surface due to insufficient bearing capacity before full development of the vertical cracks. During the crushing process, the reduction of the active bearing area rapidly reduced the bearing capacity of samples. Because it was challenging to compact the corner of the block during manufacture, this failure mode mainly appears in rammed adobe.

Table 5 shows the quantity distribution of failure mode for the two blocks calculated in three perpendicular load directions $(x, y$, and $z)$. The loading direction has significant effects on the failure mode of blocks: loading in the $x$ - and $y$ directions resulted in blocks that were more prone to shear failure and local damage. Loading in the $z$-direction can ensure the axial compression failure of samples. 


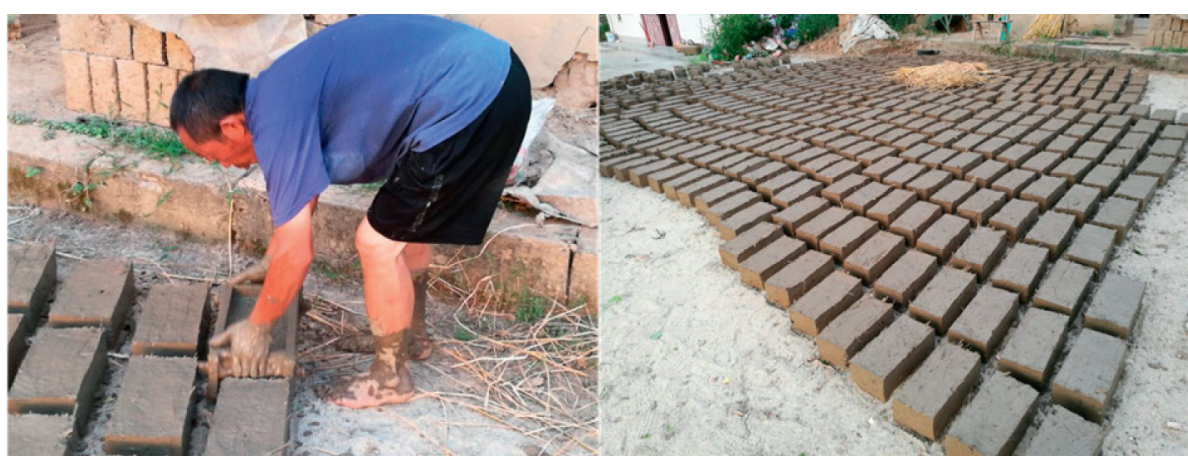

(a)

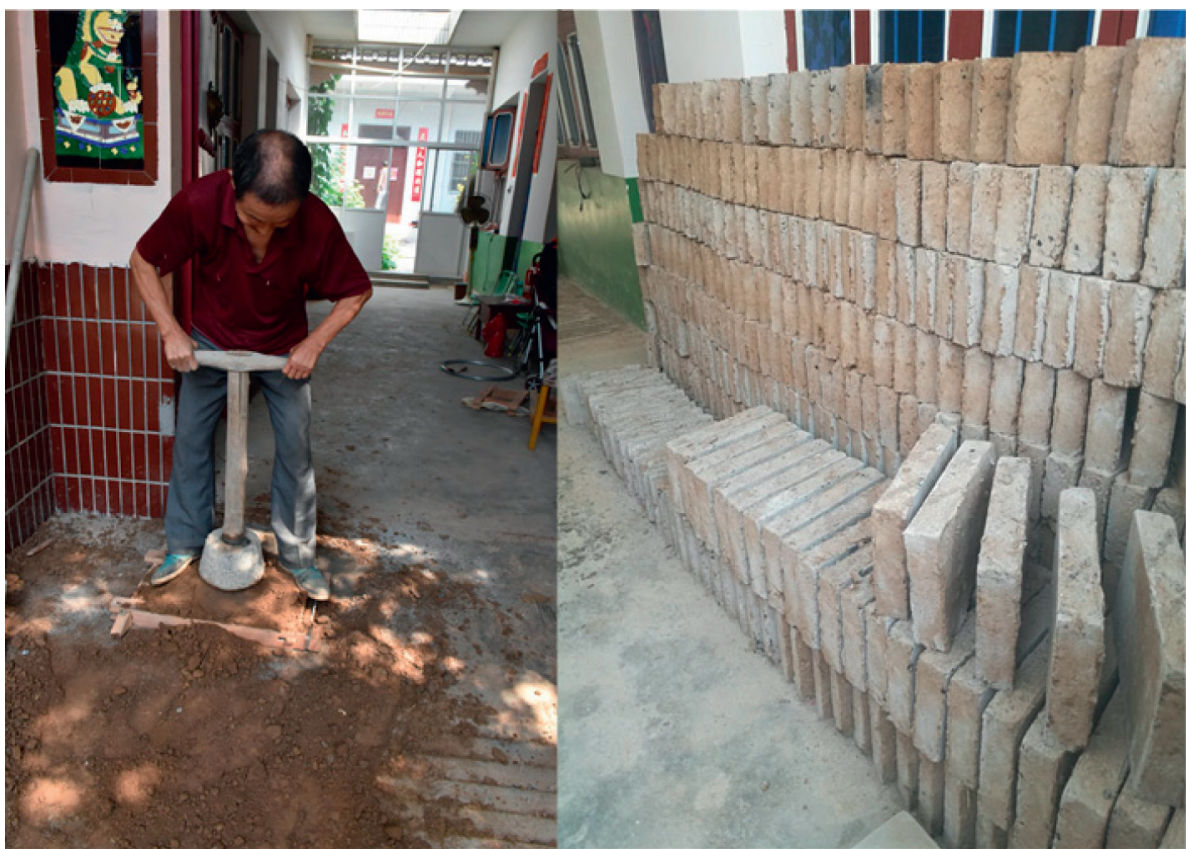

(b)

Figure 2: Manufacturing process. (a) Molded adobe. (b) Rammed adobe.

TABle 2: Dimensions and densities of the earth blocks.

\begin{tabular}{lccccc}
\hline Block & $h(\mathrm{~cm})$ & $b(\mathrm{~cm})$ & $l(\mathrm{~cm})$ & $\rho\left(\mathrm{g} / \mathrm{cm}^{3}\right)$ & \\
\hline Molded adobe & 10 & 15 & 31 & 1.65 & 3.7 \\
Rammed adobe & 6 & 24 & 37 & 1.81 & 5.3 \\
\hline
\end{tabular}

$h$ : thickness; $b$ : width; $l$ : length; $\rho$ : density; $\sigma_{\rho}$ : coefficient of variation of density.

4.2. Compression Tests on Cube Samples. The cube samples in different loading directions showed axial compressive failure. The initial crack appeared at the corner of the cubes. The corners of the cubes were crushed, and many vertical cracks appeared on the surface when the failure occurred (Figure 4).

Table 6 shows the compressive strength of molded and compressed cube samples measured in three orientations: $x$, $y$, and $z$. For each series of results, the maximum, minimum, and mean values are presented. The variability of the results is reflected by the coefficient of variation expressed in \%.

The results obtained on the molded cubes in different loading directions show a lower mean compressive strength for the cube samples than for the blocks laid horizontally. The reduction of compressive strength was mainly due to the increase of the aspect ratio from 0.67 (blocks laid horizontally) to 1 (cube). For the compressed cube samples, the compressive strength of the sample was measured as the aspect ratio increased from 0.25 (blocks laid horizontally) to 1 (cube). Table 6 shows that the compressive strength of compressed cubes depends on the loading direction, but the loading direction has no significant effect on the compressive strength of molded cubes. For molded cubes, the difference of compressive strength between three loading directions was very small, and the compressive strength ratio of three loading directions was $x: y: z=1.06: 0.98: 1$. The coefficient of 
TABle 3: Geometric dimension of samples.

\begin{tabular}{|c|c|c|c|c|c|}
\hline \multirow{2}{*}{ Test } & \multirow{2}{*}{ Loading direction } & \multicolumn{2}{|c|}{ Molded } & \multicolumn{2}{|c|}{ Compressed } \\
\hline & & Size $(\mathrm{cm})$ & Aspect ratio ${ }^{a}$ & Size $(\mathrm{cm})$ & Aspect ratio \\
\hline \multirow{3}{*}{ Full-size block } & $x$ & $15 \times 10 \times 31$ & 1.50 & $24 \times 6 \times 37$ & 4.00 \\
\hline & $y$ & $31 \times 10 \times 15$ & 3.10 & $37 \times 6 \times 24$ & 6.20 \\
\hline & $z$ & $10 \times 15 \times 31$ & 0.67 & $6 \times 24 \times 37$ & 0.25 \\
\hline \multirow{3}{*}{ Cube sample } & $x$ & $10 \times 10 \times 10$ & 1.00 & $10 \times 10 \times 10$ & 1.00 \\
\hline & $y$ & $10 \times 10 \times 10$ & 1.00 & $10 \times 10 \times 10$ & 1.00 \\
\hline & $z$ & $10 \times 10 \times 10$ & 1.00 & $10 \times 10 \times 10$ & 1.00 \\
\hline Stacked half-blocks & $z$ & $20 \times 15 \times 15$ & 1.33 & $12 \times 24 \times 18$ & 0.65 \\
\hline
\end{tabular}

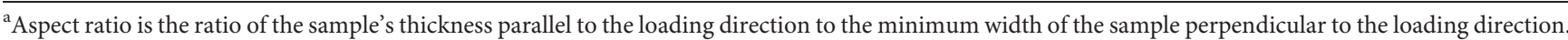

TABLE 4: Comparison of the compressive strength of full-size blocks for different load directions.

\begin{tabular}{|c|c|c|c|c|c|c|}
\hline \multirow{2}{*}{$\begin{array}{l}\text { Type of block } \\
\text { Loading direction }\end{array}$} & \multicolumn{3}{|c|}{ Molded adobe } & \multicolumn{3}{|c|}{ Rammed adobe } \\
\hline & $x$ & $y$ & $z$ & $x$ & $y$ & $z$ \\
\hline Aspect ratio & 1.5 & 3.1 & 0.67 & 4.0 & 6.2 & 0.25 \\
\hline 1 & 1.005 & 0.469 & 1.025 & 1.291 & 1.621 & Not possible \\
\hline 2 & 0.715 & 0.650 & 1.172 & 1.651 & 1.970 & \\
\hline 3 & 0.846 & 0.402 & 1.227 & 1.609 & 0.977 & \\
\hline 4 & 0.660 & 0.429 & 1.292 & 0.992 & 1.304 & \\
\hline 5 & 0.772 & 0.580 & 1.146 & 1.660 & 0.819 & \\
\hline 6 & 0.706 & 0.365 & 1.357 & 2.417 & 0.850 & \\
\hline 7 & 0.641 & 0.559 & 1.365 & 1.449 & 1.265 & \\
\hline 8 & 0.707 & 0.491 & 1.229 & 1.383 & 1.581 & \\
\hline 9 & 0.632 & 0.671 & 1.373 & 2.255 & 2.007 & \\
\hline 10 & 0.815 & 0.439 & 1.572 & 1.120 & 1.681 & \\
\hline$f_{c-\max }(\mathrm{MPa})$ & 1.005 & 0.671 & 1.572 & 0.992 & 2.007 & \\
\hline$f_{c-\min }(\mathrm{MPa})$ & 0.632 & 0.365 & 1.025 & 2.417 & 0.819 & \\
\hline$f_{\text {mean }}(\mathrm{MPa})$ & 0.750 & 0.505 & 1.276 & 1.615 & 1.407 & \\
\hline$\sigma_{f_{c}}(\%)$ & 15.3 & 20.3 & 11.4 & 28.2 & 30.3 & \\
\hline
\end{tabular}

$f_{c-\text { max }}$ is the maximum, $f_{c \text {-min }}$ is the minimum, $f_{\text {mean }}$ is the average, and $\sigma_{f c}$ is the coefficient of variation.

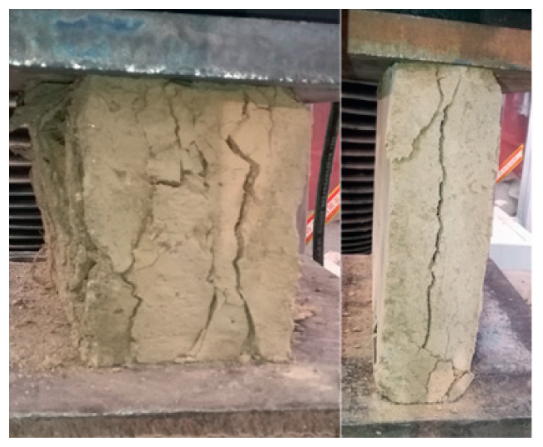

(a)

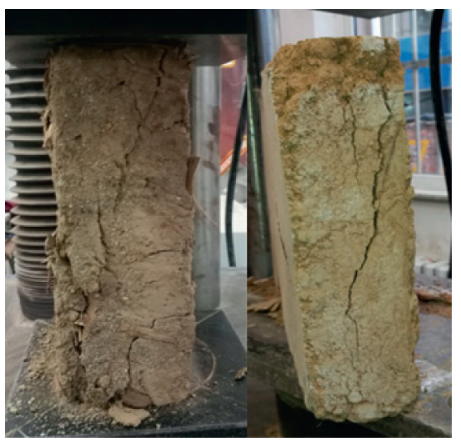

(b)

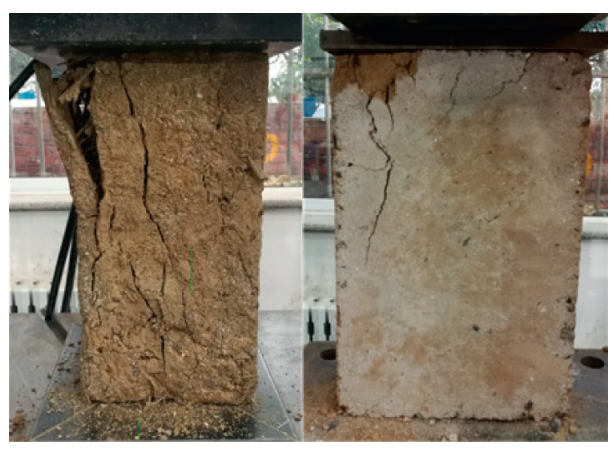

(c)

Figure 3: Failure modes of full-size blocks. In each picture, the molded adobe is shown on the left, and the rammed adobe is shown on the right. (a) Axial compression failure, (b) shear failure, and (c) local failure.

TABle 5: Distribution of failure modes.

\begin{tabular}{lccccc}
\hline Type of block & \multicolumn{2}{c}{ Molded adobe } & \multicolumn{3}{c}{ Rammed adobe } \\
Loading direction & $x$ & $y$ & $z$ & 5 & $y$ \\
\hline Axial compression failure & 8 & 4 & 10 & 2 & 3 \\
Shear failure & 2 & 4 & - & 3 & 3 \\
Local failure & - & 2 & - & - \\
\hline
\end{tabular}




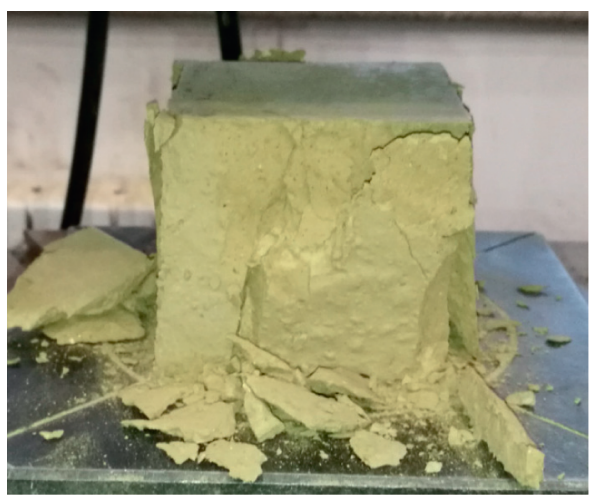

(a)

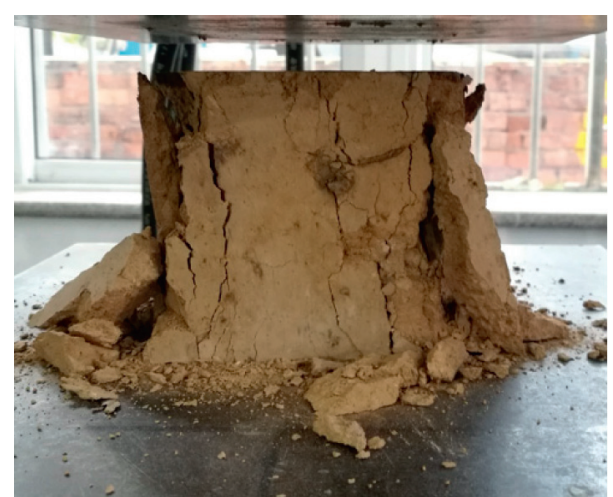

(b)

Figure 4: Failure modes of cube samples. (a) Molded adobe. (b) Rammed adobe.

TABLE 6: Compressive strength measured directly on stacked half-blocks and cube samples.

\begin{tabular}{|c|c|c|c|c|c|c|}
\hline \multirow{2}{*}{$\begin{array}{l}\text { Sample } \\
\text { Loading direction }\end{array}$} & \multicolumn{3}{|c|}{ Molded cube } & \multicolumn{3}{|c|}{ Compressed } \\
\hline & $x$ & $y$ & $z$ & $x$ & $y$ & $z$ \\
\hline$\overline{1}$ & 0.95 & 1.1 & 0.91 & 2.36 & 2.05 & 1.92 \\
\hline 2 & 1.08 & 1.02 & 0.93 & 1.79 & 1.98 & 2.23 \\
\hline 3 & 1.17 & 0.93 & 0.93 & 2.43 & 2.82 & 2.3 \\
\hline 4 & 1.01 & 0.99 & 0.98 & 1.82 & 2.34 & 2.31 \\
\hline 5 & 1.25 & 1.05 & 1.04 & 1.99 & 1.86 & 2.54 \\
\hline 6 & 1.15 & 1.11 & 1.06 & 2.15 & 2.65 & 2.64 \\
\hline 7 & 1.16 & 1.18 & 1.08 & 2.74 & 2.4 & 2.68 \\
\hline 8 & 0.96 & 1.06 & 1.1 & 2.19 & 2.45 & 2.73 \\
\hline 9 & 1.08 & 0.92 & 1.14 & 1.95 & 1.85 & 2.8 \\
\hline 10 & 1.18 & 0.88 & 1.25 & 2.37 & 2.02 & 3.03 \\
\hline$f_{c-\max }(\mathrm{MPa})$ & 1.25 & 1.18 & 1.25 & 2.74 & 2.82 & 3.03 \\
\hline$f_{c-\min }(\mathrm{MPa})$ & 0.95 & 0.88 & 0.91 & 1.79 & 1.85 & 1.92 \\
\hline$f_{\text {mean }}(\mathrm{MPa})$ & 1.10 & 1.02 & 1.04 & 2.18 & 2.24 & 2.52 \\
\hline$\sigma_{f_{c}}(\%)$ & 9.1 & 9.2 & 10.2 & 13.8 & 15.1 & 12.0 \\
\hline
\end{tabular}

$f_{c-\text { max }}$ is the maximum, $f_{c \text {-min }}$ is the minimum, $f_{\text {mean }}$ is the average, and $\sigma_{f c}$ is the coefficient of variation.

variation of the compressive strength measurements for molded cube samples in different loading directions ranged from $9.1 \%$ to $10.2 \%$, lower than those for the molded adobes laid horizontally (11.4\%). For the compressed cube samples, the compressive strengths measured in the $x$ - and $y$-direction were both less than that measured in the $z$-direction, and the compressive strength ratio for the three loading directions was $x: y: z=0.87: 0.89: 1$. The variations of compressive strength measured in the $x$ - and $y$-directions were also larger than that in $z$-direction.

4.3. Compression Tests on Stacked Half-Blocks. The two kinds of stacked half-blocks both exhibited axial compression failure. The initial cracks appeared on the contact surfaces of the two blocks, followed by cracking at the corner of the specimen. Finally, vertical cracks penetrated the sample, and the surface of the sample was peeled off (Figure 5).

Table 7 shows the compressive strength of molded and compressed stacked half-blocks measured in the $z$-direction. For each series of results, the maximum, minimum, and mean values are presented. The variability of the results is reflected by the coefficient of variation expressed in $\%$.
The aspect ratio of the sample was significantly increased by half-block stacking, and the values of molded adobes and rammed adobes increased by 0.67 and 0.4 , respectively, compared with that of the blocks laid horizontally. For molded adobe, the increase in the aspect ratio reduced the compressive strength from $1.28 \mathrm{MPa}$ to $0.76 \mathrm{MPa}$. Interestingly, the inability to measure the compressive strength of rammed adobe was successfully alleviated by half-block stacking. Additionally, as in the test on stacked molded halfblocks, the variability of the compressive strength was slightly increased compared to that measured for full-size blocks laid horizontally. This may be due to varying degrees of damage to the blocks due to sawing.

\section{Discussion}

Table 8 shows the mean compressive strength measurements for various types of samples. There are significant differences in the results obtained from the experiment conducted on full-size blocks in different loading directions. For molded adobe, the ratios between the compressive strength measured in the $z$-direction to that measured in the $x$ - and $y$ directions were 1.7 and 2.5 , respectively. This remarkable 


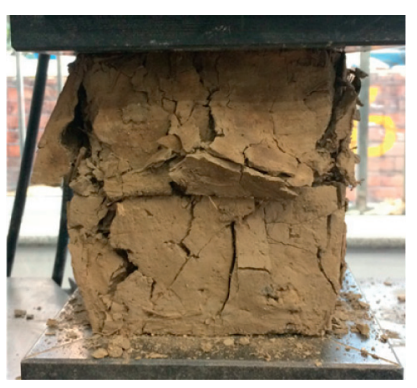

(a)

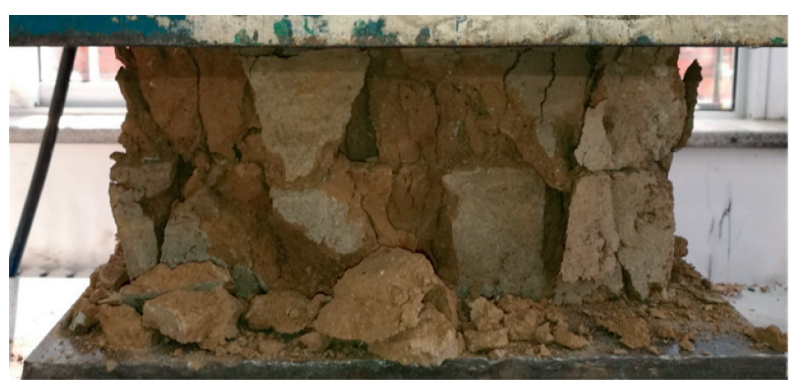

(b)

FIGURE 5: Failure modes of stacked half-blocks. (a) Molded adobe. (b) Rammed adobe.

TABLE 7: Compressive strength measured directly on stacked halfblocks and cube samples.

\begin{tabular}{lcc}
\hline Type of block & Molded & Compressed \\
\hline Aspect ratio & 1.33 & 0.65 \\
1 & 0.60 & 1.96 \\
2 & 0.68 & 1.80 \\
3 & 0.71 & 2.23 \\
4 & 0.72 & 2.26 \\
5 & 0.73 & 2.35 \\
6 & 0.73 & 2.95 \\
7 & 0.81 & 2.36 \\
8 & 0.81 & 2.41 \\
9 & 0.83 & 2.75 \\
10 & 0.96 & 2.91 \\
$f_{c-\text { max }}(\mathrm{MPa})$ & 0.96 & 2.95 \\
$f_{c-\min }(\mathrm{MPa})$ & 0.60 & 1.80 \\
$f_{\text {mean }}(\mathrm{MPa})$ & 0.76 & 2.40 \\
$\sigma_{f c}(\%)$ & 11.9 & 15.4 \\
\hline
\end{tabular}

$f_{c-\text { max }}$ is the maximum, $f_{c-\text { min }}$ is the minimum, $f_{\text {mean }}$ is the average, and $\sigma_{f c}$ is the coefficient of variation.

anisotropy of full-size molded adobe was due to the variation of aspect ratio and failure mode with loading direction. The uncertainty of failure mode led to difficulty in determining the anisotropy factor accurately. For rammed adobe, because the aspect ratio of full-size blocks laid horizontally is small (0.25), the compressive strength cannot be measured. The change of loading direction also affects the relative relationship (parallel or perpendicular) between loading direction and ramming direction, making determination of the anisotropy factor more difficult. Accordingly, the compression test on full-size blocks is only suitable for blocks with high aspect ratio, and to ensure the axial compression failure of the blocks, the loading direction should be parallel to the thickness direction of the blocks.

For cube samples, the anisotropy of compressive strength was weakened. The ratios of compressive strength measured in different directions are close to 1 . This shows that the aspect ratio effect on compressive strength can be avoided by testing cube samples of uniform size, allowing comparison of the compressive strength of different kinds of earth blocks (molded, compressed, and extruded). Although the unified cube samples eliminated the size effect on the compressive strength of block, the compressive strength cannot be separated from the size of the block since the size is determined by the manufacturing process. For example, a minimal thickness of the rammed adobe was used to determine the degree of compaction, and substantial thickness was used to prevent excessive deformation of molded adobe. The cube specimens used in this experiment are all made with the same manufacturing process and raw materials as adobe. The variation of compressive strength in the triaxial direction is similar. However, it is often impossible for the existing traditional adobe to use the same process and raw materials as the block to make the specimen again. Aubert's research results [13] show that it is tough to cut the standard size specimen from the complete block. Moreover, the vibration generated in the cutting process will cause damage to the block and increase the discreteness of the test results. The compressive strength of the specimen with uniform shape and size is used to represent the strength of the adobe, which seems to ensure the comparability of the test data, but it is not the actual strength of the adobe. Therefore, this strength test method can only be used for the strength comparison of earth materials and cannot represent the actual strength of the earth block.

The use of stacked half-blocks effectively allows compressive strength measurement of small aspect ratio blocks. The compressive strength measured by this method reflects the size effect of blocks, making it the most realistic value of compressive strength. However, the vibration produced by sawing affects measurement the compressive strength of blocks. Therefore, to measure a block with high aspect ratio, it is preferable to perform the test directly on full-size blocks laid horizontally. The German standard (DIN 18945 2013) recommends measuring the compressive strength of blocks with thickness greater than $71 \mathrm{~mm}$ by full-size blocks laid horizontally. The molded adobes in this study meet these guidelines, and the compressive strength is obtained by direct compression on the full-size block. However, it is unreasonable to specify the thickness of the brisk without considering the compression area. If the sectional dimension of the block is very large, the "critical thickness" should be appropriately increased.

The corresponding relationship between compressive strength and height-to-thickness ratio of different specimens in this test is plotted in Figure 6. The test data of two types of adobe specimens are fitted. It can be seen from Figure 6 that the compressive strength of various specimens decreases with the increase of height-to-thickness ratio. The influence 
TABLE 8: Synthesis of the mean compressive strength measured on various samples.

\begin{tabular}{lcccc}
\hline Samples & \multicolumn{2}{c}{ Molded } & \multicolumn{2}{c}{ Compressed } \\
& Aspect ratio & $f_{\text {mean }}(\mathrm{MPa})$ & Aspect ratio & $f_{\text {mean }}(\mathrm{MPa})$ \\
\hline Full-size block $(x$-direction) & 1.50 & 0.75 & 4.00 & 1.62 \\
Full-size block ( $y$-direction) & 3.10 & 0.51 & 6.20 & 1.41 \\
Full-size block ( $z$-direction) & 0.67 & 1.28 & 0.25 & - \\
Cube $(x$-direction) & 1.00 & 1.10 & 1.00 & 2.18 \\
Cube $(y$-direction) & 1.00 & 1.02 & 1.00 & 2.24 \\
Cube $(z$-direction) & 1.00 & 1.04 & 1.00 & 2.52 \\
Stacked half-blocks & 1.33 & 0.76 & 0.65 & 2.40 \\
\hline
\end{tabular}

$f_{\text {mean }}$ is the average.

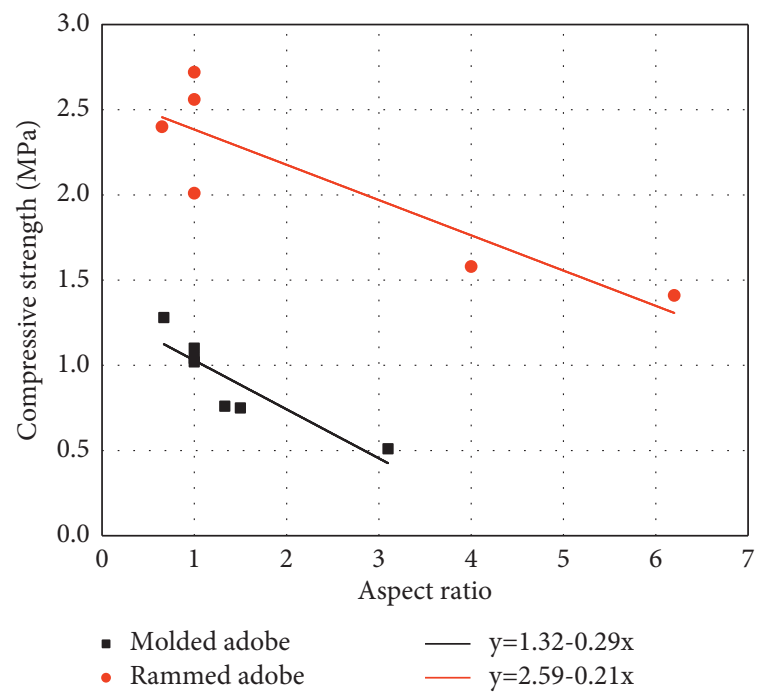

FIgURE 6: Mean compressive strength versus aspect ratio for various samples.

of the height-to-thickness ratio on the compressive strength of the specimen is essential that there are differences in the hoop effect of the specimens with different height-tothickness ratios. To consider the influence of the height-tothickness ratio of the specimen, scholars refer to the strength conversion method of the fired brick and propose using the strength conversion coefficient to reflect the influence of the height-to-thickness ratio on the compressive strength. However, there are still many controversies about using a single conversion factor to convert different height-tothickness ratio blocks. First of all, the size of the earth block is closely related to its manufacturing process (especially for adobe). It is meaningless to compare the compressive strength after coefficient conversion as the representative strength of the block, which can only represent the strength of materials. Secondly, using a single strength conversion factor only emphasizes the influence of the height-tothickness ratio of the specimen on its compressive strength. Still, it weakens the difference of the material itself. Even if the change of height-to-thickness ratio is the same, the compressive strength of different earth materials may show different trends, which a fixed strength conversion factor cannot reflect. Accordingly, when testing the compressive strength of the earth block, the compressive strength value affected by the height-to-thickness ratio can be regarded as a part of the actual strength of the block, and there is no need to use the conversion factor to convert it.

\section{Conclusion}

To put forward a simple, standardized, and practical compressive test method of earth block, this paper uses two kinds of traditional adobe to make different specimens for the compressive strength test. The following main conclusions are obtained, which can be used to reference subsequent research and design personnel to select the compressive strength test method of earth block.

(1) Direct loading along the thickness direction of the full-size block is preferred to test the compressive strength of the earth block. It is easy to cause nonaxial compression failure such as shear compression failure or local failure when the full-size block is tested along the length and width direction of the block. At the same time, the compressive strength obtained by this method has evident dispersion, so it is not suitable to be used as the strength test method of earth block. The nonbrittleness of the earth block and hoop effect makes it impossible to measure the compressive strength of small thickness block along the direction of block thickness. However, the compressive strength measured by this test method is close to the actual strength of the block. Therefore, it is suggested that the test method should be preferred to test the compressive strength of the earth block.

(2) The standard specimen obtained by cutting the fullsize block is not suitable for the test of the compressive strength of the earth block. The method of obtaining the standard specimen from the full-size block by cutting causes damage to the specimen and makes it difficult to control its size accurately. The compressive strength of specimens with uniform shape and size can only reflect the strength of materials but cannot represent the actual strength of the earth block.

(3) It can effectively solve the problem that the compressive strength of the small-thickness earth block cannot be directly measured by cutting the fullsize block in half and stacking it, but it is not 
recommended to use the binder to bond the two half-blocks. The binder with higher moisture content may lead to the softening of the earth block, and the fullness of the mortar joint is greatly affected by the test personnel. Therefore, it is not recommended to use a binder to bond the two half-blocks. Simply stacking two half-blocks is easy to operate and suitable for earth blocks with good surface smoothness.

(4) When comparing the compressive strength of the earth blocks, the conversion coefficient related to the height-to-thickness ratio of the specimen cannot be used to convert the compressive strength. Still, the anisotropy of the material strength should be considered. The compressive strength of rammed adobe shows apparent anisotropy. The compressive strength of the cube specimen perpendicular to the ramming direction is about 1.3 times that parallel to the ramming direction.

\section{Data Availability}

The raw/processed data used to support the findings of this study are included within the article.

\section{Conflicts of Interest}

The authors declare that they have no conflicts of interest regarding the publication of this study.

\section{Acknowledgments}

This research work was supported by the Science Fund for Creative Research Groups of the National Natural Science Foundation of China (Grant no. 51478043) and the Natural Science Basic Research Program of Shaanxi Province (in China) (Grant no. 2020JM-536).

\section{References}

[1] J. C. Morel, A. Mesbah, M. Oggero et al., "Building houses with local materials: means to drastically reduce the environmental impact of construction," Building and Environment, vol. 10, no. 1, pp. 1119-1126, 2001.

[2] H. M. Algin and P. Turgut, "Cotton and limestone powder wastes as brick material," Construction and Building Materials, vol. 22, no. 6, pp. 1074-1080, 2008.

[3] H. Y. Ghorab, A. Anter, and H. El Miniawy, "Building with local materials: stabilized soil and industrial wastes," Materials and Manufacturing Processes, vol. 22, no. 2, pp. 157-162, 2007.

[4] J. Zhang, W. Xu, A. Li, K. Zheng, and J. Zhang, "Modified method for evaluating improved technologies for indoor thermal environment of earth buildings," Building and Environment, vol. 144, no. 144, pp. 673-681, 2018.

[5] M. R. Hall and W. Swaney, "European modern earth construction," Modern Earth Buildings, Woodhead Publishing Series In Energy, Cambridge, England, 2012.

[6] H. Van Damme and H. Houben, "Earth concrete. Stabilization revisited," Cement and Concrete Research, vol. 114, no. 1, pp. 90-102, 2018.
[7] G. Sarangapani, B. V. Venkatarama Reddy, and K. S. Jagadish, "Brick-mortar bond and masonry compressive strength," Journal of Materials in Civil Engineering, vol. 17, no. 2, pp. 229-237, 2005.

[8] G. Mohamad, F. S. Fonseca, A. T. Vermeltfoort, D. R. W. Martens, and P. B. Lourenço, "Strength, behavior, and failure mode of hollow concrete masonry constructed with mortars of different strengths," Construction and Building Materials, vol. 134, no. 1, pp. 489-496, 2017.

[9] J. A. Thamboo and M. Dhanasekar, "Correlation between the performance of solid masonry prisms and wallettes under compression," Journal of Building Engineering, vol. 22, no. 1, pp. 429-438, 2019.

[10] G. A. Parsekian, F. S. Fonseca, G. L. Pinheiro et al., "Properties of mortar using cubes, prism halves, and cylinder specimens," ACI Materials Journal, vol. 111, no. 4, pp. 443-454, 2014.

[11] D. Ciancio and J. Gibbings, "Experimental investigation on the compressive strength of cored and molded cementstabilized rammed earth samples," Construction and Building Materials, vol. 28, no. 1, pp. 294-304, 2012.

[12] D. Silveira, H. Varum, and A. Costa, "Influence of the testing procedures in the mechanical characterization of adobe bricks," Construction and Building Materials, vol. 40, no. 3, pp. 719-728, 2013.

[13] J. E. Aubert, P. Maillard, J. C. Morel, and M. Al Rafii, “Towards a simple compressive strength test for earth bricks?" Materials and Structures, vol. 49, no. 5, pp. 1641-1654, 2016.

[14] R. Illampas, I. Ioannou, and D. C. Charmpis, "Adobe bricks under compression: e," Construction and Building Materials, vol. 53, no. 4, pp. 83-90, 2014.

[15] B. V. V. Reddy, S. M. Rao, and M. K. A. Kumar, "Characteristics of stabilized mud blocks using ash-modified soils," Indian Concrete Journal, vol. 77, no. 2, pp. 903-911, 2003.

[16] German Institute for Standardization, Earth blocks-Terms and Definitions, Requirements, Test Methods, DIN 18945, German Institute for Standardization, Berlin, Germany, 2013.

[17] H. Yu, L. Zheng, J. Yang, and L. Yang, "Stabilised compressed earth bricks made with coastal solonchak," Construction and Building Materials, vol. 77, no. 1, pp. 409-418, 2015.

[18] P. M. Touré, V. Sambou, M. Faye, A. Thiam, M. Adj, and D. Azilinon, "Mechanical and hygrothermal properties of compressed stabilized earth bricks (CSEB)," Journal of Building Engineering, vol. 13, no. 1, pp. 266-271, 2017.

[19] J.-C. Morel, A. Pkla, and P. Walker, "Compressive strength testing of compressed earth blocks," Construction and Building Materials, vol. 21, no. 2, pp. 303-309, 2007.

[20] AFNOR, Blocs de Terre Comprimée Pour Murs et Cloisons: Définitions-Spécifications-Méthodes d'essais-Conditions de Réception, XP P13-901, Association Francaise de Normalisation (AFNOR), Paris, France, 2001.

[21] J. C. Morel and A. Pkla, "A model to measure compressive strength of compressed earth blocks with the ' 3 points bending test," Construction and Building Materials, vol. 16, no. 5, pp. 303-310, 2002.

[22] P. J. Walker, "Strength, durability and shrinkage characteristics of cement stabilised soil blocks," Cement and Concrete Composites, vol. 17, no. 4, pp. 301-310, 1995.

[23] E. Adorni, E. Coïsson, and D. Ferretti, "In situ characterization of archaeological adobe bricks," Construction and Building Materials, vol. 40, no. 3, pp. 1-9, 2013.

[24] P. Vega, A. Juan, M. Ignacio Guerra, J. M. Morán, P. J. Aguado, and B. Llamas, "Mechanical characterisation of traditional adobes from the north of Spain," Construction and Building Materials, vol. 25, no. 7, pp. 3020-3023, 2011. 
[25] Q. Piattoni, E. Quagliarini, and S. Lenci, "Experimental analysis and modelling of the mechanical behaviour of earthen bricks," Construction and Building Materials, vol. 25, no. 4, pp. 2067-2075, 2011

[26] G. Ruiz, X. Zhang, W. F. Edris, I. Cañas, and L. Garijo, “A comprehensive study of mechanical properties of compressed earth blocks," Construction and Building Materials, vol. 176, no. 5, pp. 566-572, 2018.

[27] Y. Millogo, J.-E. Aubert, A. D. Séré, A. Fabbri, and J.-C. Morel, "Earth blocks stabilized by cow-dung," Materials and Structures, vol. 49, no. 11, pp. 4583-4594, 2016.

[28] Specification of Soil Test, SL237-1999, Ministry of Water Resources of the PRC, China Water Power Press, Beijing, China, 1999.

[29] Test Methods for wall Blocks, GB/T2542-2012, General Administration of Quality Supervision, Inspection and Quarantine of the PRC, Standards Press of China, Beijing, China, 2013. 